\title{
As micro-histórias e os regimes de (in)visibilidade dos anônimos em Pé na cova ${ }^{1}$
}

\author{
Mário Francisco Ianni Viggiano²
} 06 e 07 de novembro de 2013. 


\section{Resumo}

Palavras-chave

Anônimos, (in)visibilidade, micro-histórias, Pé na cova.

\section{Abstract}

Este artigo apresenta um estudo sobre os regimes de (in)visibilidade dos anônimos de Pé na cova, seriado de televisão brasileiro exibido pela Rede Globo, escrito por Miguel Falabella. Os episódios foram analisados a partir de referenciais teóricos como o de micro-história de Giovanni Levi e Carlo Ginzburg, e de subúrbio. O objetivo foi tentar compreender os regimes de (in)visibilidade e as imagens construídas pelas narrativas ficcionais dos personagens do seriado, entendidos aqui como anônimos, que direta ou indiretamente sobrevivem graças às pessoas que morrem no bairro do Irajá, subúrbio do Rio de Janeiro. E como, por meio de uma narrativa recheada de linguagem nonsense utilizada por eles, são discutidos valores e princípios da sociedade brasileira.

This paper presents a study about the schemes of (in)visibility of anonymous in Pé na cova, Brazilian television sitcom broadcast by Rede Globo, written by Miguel Falabella. The episodes were analyzed according to theoretical references such as micro history, a notion by Giovanni Levi and Carlo Ginzburg, and suburbs. Our goal was to try to understand the (in)visibility schemes and images constructed by the fictional narratives of the characters of the series, understood here as anonymous, which directly or indirectly survive thanks to the people who die in the neighborhood of Irajá, Rio de Janeiro suburb. Moreover, how values and principles of the Brazilian society are discussed through a narrative filled with nonsense language used by them.

\section{Keywords}

Anonymous, (in)visibility, micro-histories, Pé na cova. 
Este trabalho faz parte de uma série de estudos que vêm sendo realizados sobre a visibilidade dos anônimos, neste caso a visibilidade midiática em um seriado de TV, e em particular sobre as práticas discursivas em relação ao tema. O objetivo do artigo foi tentar compreender as micro-histórias, os regimes de (in)visibilidade e as imagens construídas pelas narrativas ficcionais dos personagens do seriado de televisão brasileiro Pé na cova, exibido pela Rede Globo e escrito por Miguel Falabella, entendidos aqui como anônimos, que direta ou indiretamente sobrevivem graças às pessoas que morrem no bairro do Irajá, subúrbio do Rio de Janeiro. Em termos de referenciais teóricos, para analisar os episódios, foram articulados conceitos de micro-história e invisibilidade dos anônimos segundo Giovanni Levi (1992) e Carlo Ginzburg (2007) e conceitos relacionados ao subúrbio, neste caso, da cidade do Rio de Janeiro.

\section{Micro-histórias do subúrbio carioca e do bairro do Irajá}

\section{"(...) não há cidadania sem memória, e não há memória sem arte...".} (autor desconhecido)

Imagens aéreas de um Rio de Janeiro mundialmente conhecido pelos pontos turísticos aos poucos ganham velocidade e, aceleradas, apontam o passar do tempo e do espaço, voltam à velocidade normal, vão se fechando e se aproximando em um mergulho, um zoom vertiginoso, em direção à outra referência geográfica, identificada por uma placa da estação do metrô. O destino é o bairro do Irajá. Uma trilha sonora dá o tom, auxilia a contextualização e delimitação, em termos de espacialidade e de temporalidade, das ações que estão prestes a se desenrolarem um episódio de Pé na cova (2013), seriado semanal que está na segunda temporada e que é apresentado atualmente pela Rede Globo nas noites de terça-feira.

Em um processo semelhante ao do examinar uma superfície com uma lupa, é possível perceber em Pé na cova as perspectivas propostas por Levi (1992) e Ginzburg (2007) sobre micro-história, ao se realizar uma observação 
e descrição etnográfica em escala reduzida de temáticas ligadas ao cotidiano de comunidades específicas, neste caso da família Pereira e dos vizinhos do Irajá, reconstituindo microcontextos e mostrando personagens extremos e anônimos que passariam despercebidos na multidão. Mas antes de falar sobre as aventuras da família Pereira, é necessário apresentar, mesmo que resumidamente, outras duasmicro-histórias que se afunilam, se cruzam e se misturam: a micro-história do subúrbio do Rio de Janeiro e do próprio bairro do Irajá.

Não é novidade que a cidade do Rio de Janeiro é conhecida mundialmente, tem muitos pontos turísticos e uma beleza que a consagraram como "cidade maravilhosa". Mas é também caracterizada por um crescimento desordenado e que acabou por provocar divisões geográficas, e porque não dizer sociais, de zona norte e zona sul, de áreas nobres e o subúrbio, caracterizando uma cidade partida, na concepção dos antropólogos, sociólogos e jornalistas. Ou ainda fragmentada, multifacetada, em um contexto menos científico e mais pop, evidenciado na letra de "Rio, 40 graus", de Fausto Fawcett, Fernanda Abreu e Laufer (1992) como "uma cidade de cidades misturadas, uma cidade de cidades camufladas"; "cidade maravilha, purgatório da beleza e do caos"; "capital do sangue quente do melhor e do pior do Brasil...".

O que dizer, então, do subúrbio. Historicamente, no século XIX, as áreas exteriores ao centro se caracterizavam como "arrabaldes", com ruas sem calçamento, cercadas de mato e poucas casas, pequenas e sujas. Lima Barreto (1977, p. 30), em Calvários e porres do pingente, descreve o subúrbio como o "o refúgio dos infelizes, os que perderam o emprego, as fortunas; os que faliram nos negócios, enfim, todos os que perderam a sua situação normal vão alinhar-se lá".

Com o crescimento das exportações e chegadas de estrangeiros, os arrabaldes foram se desenvolvendo e se transformando nos bairros. O Rio se urbaniza e nas duas primeiras décadas do século XX o subúrbio deixa de representar todos os espaços circunvizinhos e se fixa no norte e oeste servido pelas ferrovias - como lugar do proletariado (FERNANDES, 1996 apud SILVA, 2010, p. 165). Nesse período, verifica-se que as freguesias suburbanas de Inhaúma e Irajá, bairros mais distantes do Centro, foram as que mais cresceram. 
Hoje, o subúrbio carioca compreende a região de bairros populares cortada pelas linhas de trem das antigas Central do Brasil, Leopoldina e a extinta linha auxiliar Rio D'Ouro. O sentido da palavra no Rio de Janeiro é diferente do empregado nos Estados Unidos e na Europa em função dos trens estarem ligados lá às pessoas de classe média e alta.

Mas o sentido atual do termo "suburbano" nos dicionários perde, em parte, o sentido de localidade e espacialidade para se transformar em uma categoria social. De acordo com Maciel (2010, p. 193-194), carrega ainda uma carga histórica de preconceitos e discriminação social da pobreza na cidade, da ausência de direitos, e de um sentido particular de ausência de refinamento de hábitos, falta de bom gosto ou civilidade que seriam próprios, característicos ou inerentes aos moradores desses bairros.

As representações sobre o subúrbio carioca no jornalismo, na literatura, na dramaturgia, de acordo com Souza (2010), mostram essa parte da cidade como um lugar de pobres sem a finesse dos bem nascidos.

\footnotetext{
As mulheres suburbanas são invariavelmente manicuras, cabeleireiras, babás, cozinheiras, operárias de fábricas; seus companheiros, machões grosseiros, malandros e ciumentos. Elas enxergam nos moradores da Zona Sul seus príncipes encantados que vão tirá-las de suas vidinhas suburbanas. Os homens suburbanos, por sua vez, são motoristas (de madame, ônibus ou táxi), balconistas, funcionários públicos de baixa qualificação, mecânicos (quase sempre com peito cabeludo à mostra) e bicheiros - atualmente foi incluída nessa seleta fauna a figura do miliciano. Todos têm em comum, além da pouca instrução, a postura machista, a malandragem etc. (SOUZA, 2010, p. 226).
}

É importante dizer que esses personagens suburbanos se constituíram em uma seleta fauna, cuja caracterização é riquíssima em detalhes em $A$ vida como ela é (2012) e outras obras de Nelson Rodrigues. E na música de Chico Buarque, na figura do malandro e de tantos outros personagens, e até mesmo a caracterização do espaço em que eles vivem, como em "Subúrbio" (2006): 
Lá não tem brisa/ Não tem verde-azuis/ Não tem frescura nem atrevimento/ Lá não figura no mapa/ No avesso da montanha, é labirinto/ É contra-senha, é cara a tapa/ Não tem turistas/ Não sai foto nas revistas/ Lá tem Jesus/ E está de costas/ Lá não tem claro-escuro/ A luz é dura/ A chapa é quente/ Que futuro tem/ Aquela gente toda.

No entanto, não se pode e não se deve perder de vista que o subúrbio também é o espaço da diversidade, de muitas outras formas de existir, viver, de combater e de resistir a seu modo aos valores hegemônicos.

Quanto às origens do bairro do Irajá, os sites apontam um "lugar que dá (faz) mel", nome dado pelos índios empregados no trabalho dos engenhos de açúcar. Por desconhecer o produto, acreditavam ser semelhante a mel por ser doce. Os primeiros colonos da região que usavam a "língua geral" compilada pelos jesuítas acabaram por consagrar o nome. No século XVII, o Irajá foi um centro de abastecimento importante de alimentos e material de construção e como outras sesmarias, foi desmembrada até chegar à forma do mapa atual da cidade.

Com a abertura da avenida Brasil, surgiram os grandes conjuntos habitacionais, além do Ceasa, centro de abastecimento de gêneros alimentícios inaugurado em 1974. O núcleo principal do bairro é a praça Nossa Senhora da Apresentação, onde ficam o cemitério de Irajá - inicialmente da irmandade, inaugurado em 1835, e depois substituído pelo cemitério municipal, construído entre 1894-1895 -, a igreja Nossa Senhora da Apresentação - tombada pelo Patrimônio Cultural do Rio de Janeiro - e o Instituto Jesus Eucarístico.

Uma das figuras importantes da região foi dom Manuel de Monte Rodrigues, o conde de Irajá, falecido em 1863. Ele foi deputado pela província e bispo do Rio de Janeiro, em 1839, e sagrou e coroou Dom Pedro II. O bairro hoje é essencialmente residencial, considerado de classe média, com cerca de 100 mil habitantes, e as famílias tradicionais são: Bral, Campos, Gamas, Borges, Matos, Tavares e Esteves.

\section{O outro lado da propaganda de margarina}

Depois de descobrir o potencial de audiência da classe C e dar visibilidade a ela, a Rede Globo, assim como Greta Garbo, quem diria, acabou 
no Irajáa. Pé na cova (2013) tem como estrutura central as aventuras da família Pereira, que mora no subúrbio, mais especificamente no bairro do Irajá, chefiada por Gedivan Pereira, mais conhecido como Ruço, personagem de Miguel Falabella, proprietário da F.U.I. (Funerária Unidos do Irajá).

Na mesma casa moram ele, a ex-mulher, Darlene, personagem de Marília Pêra, que é alcoólatra e trabalha como maquiadora de defuntos; o filho, Alessanderson, representado por Daniel Torres, um jovem que ingressa na carreira política e é pai do Bolsa Funerária; a filha stripper, Odete Roitman, representada por Luma Costa; Abigail ou Bibi, atual mulher de Ruço, personagem de Lorena Comparato, uma menina órfã que é trinta anos mais nova e Isaura, a Bá, uma babá velha muito maluca.

A família ainda tem uma empregada ainda mais pobre, verdadeiramente miserável, a Adenóide, personagem de Sabrina Korgut. Na segunda temporada, chegaram o filho de Ruço e Bibi, Neymã, em homenagem a Neymar e Cauã Reymond, e Sermancino, filho adotivo de Tamanco e Odete, guia turístico do cemitério que ganha dinheiro de turistas mostrando os túmulos de Greta Garbo e do cantor Antônio Marcos.

Na funerária ainda trabalham Juscelino Souza e Silva, o quasímodo ou "quasimo", o motorista do carro funerário, interpretado por Alexandre Zacchia, e a carpideira freelancer Luz Divina, funcionária pública aposentada. Na oficina mecânica vizinha à casa dos Pereira estão os mecânicos Cristiane/Tamanco, personagem de Mart'nália, namorada de Odete Roitman e Marcão/Markassa, travesti à noite, interpretado por Maurício Xavier.

Já o "Cachorras Quentes" é um trailer de sanduíches, uma lanchonete "ponto de encontro" dos personagens, que serve desde o cafezinho com pão com manteiga até pratos inusitados (um sanduíche com o nome de "x-túmulo", por exemplo) comandado pelas gêmeas não idênticas, uma branca e outra negra, Giussandra e Soninja. E para vigiar e atormentar a vida deles todos estão Floriano e Dircéia, defendendo os valores e a moral da tradicional família brasileira. 
Mas a funerária não é o bastante para prover o sustento da família Pereira e todos têm de se virar para sobreviver como podem. A filha, Odete Roitman, por exemplo, complementa a renda familiar com um trabalho bem diferente: stripteases pela internet. Apesar da referência ao nome da maior vilã da telenovela brasileira, Odete está mesmo mais para a Kátia Flávia, a godiva do Irajá, "uma loiraça belzebu gostosona e provocante que só usa calcinhas comestíveis e calcinhas bélicas, dessas com armamentos bordados", na concepção de Fausto Fawcett (1992). E no episódio em que a funerária foi interditada, ela não teve outra saída se não dar um jeito e criar uma produtora de vídeos pornôs: a F.U.I.CKYOU.

\section{Os regimes de (in)visibilidade dos anônimos em Pé na cova}

Logo na abertura do primeiro episódio de Pé na cova (2013) o tema (in)visibilidade dos anônimos é abordado. Depois da exibição das imagens do Rio de Janeiro "maravilhoso", ao som da música "Aquarela do Brasil" em inglês, a câmera mostra os personagens que surgem e compõem a situação típica de uma propaganda de margarina. A família se senta à mesa para tomar o café da manhã. Em movimento de afastamento da lente, o zoom out, aparece a tela de uma televisão sem som. Em outro movimento, de contra plano, a câmera que parece estar dentro da tela da TV mostra o outro lado do espelho, sem nenhum glamour, e "apresenta" a família Pereira. Depois de falarem sobre o som e o uso do controle remoto, começa a discussão sobre a (in)visibilidade.

A empregada, Adenóide, inicia a conversa admirando a família do anúncio de margarina. Mas logo em seguida questiona se existe gente assim e se posiciona dizendo que tudo ali é de mentira. Principalmente porque onde eles estão faz um calor danado e os personagens do comercial pareciam "fresquinhos". Ruço tenta explicar que lá, na televisão, tem ar-condicionado e que eles ficam até "gelados". Adenóide continua a indagação e convida Soninja a dar a opinião. Soninja faz o comentário: "eles existem, sabem que a gente existe e fingem que não sabem". Adenóide reafirma: "o lado de lá não sabe que o lado de cá existe". Ruço então pede a opinião do filho Alessanderson sobre o assunto ao que ele responde: "acho que não. Nós estamos do outro lado do espelho". 
Uma pausa para citar aqui a influência e a referência a I love lucy (1951) e à Rosa púrpura do Cairo, de Woody Allen (1985). No caso do seriado americano, Miguel Falabella já admitiu ser fã e faz alusões à série por meio das situações cotidianas abordadas e o caráter "desajeitado" e até pretensamente "ingênuo" de alguns personagens. Já quanto ao filme de Woody Allen, percebe-se a referência quanto à ilusão/questionamento do mundo da TV, e não do cinema como no filme, principalmente pela empregada Adenóide.

Mas isso é só o início de uma discussão que se desenvolve e se repete em quase todos os episódios. As situações cotidianas, como a falta de dinheiro, as dificuldades de viver no subúrbio, a questão da tolerância e da diversidade, a vida do outro lado da cidade e do aparelho da televisão.

Miguel Falabella, autor, e Cininha de Paula, diretora, afirmam que em Pé na cova a morte circunda, mas não protagoniza o seriado. O autor assume ter decidido ir mais fundo no Brasil para falar para os esquecidos, uma grande fatia da população relegada à marginalidade. Os personagens protagonizam o outro lado do espelho, da tela da TV, o outro lado da propaganda de margarina, o lado B da Grande família.

Mas por que o lado B da Grande família? No primeiro e longevo seriado, criado na década de 1970 por Oduvaldo Vianna Filho e Armando Costa, se apresenta o cotidiano e as aventuras dos Silva, uma família de classe média brasileira, moradora de um subúrbio na zona norte do Rio de Janeiro. Há uma discussão dos temas importantes da sociedade como a honestidade, o viver dignamente dentro de certos princípios éticos e morais, mesmo que haja o transgressor, caracterizado muitas vezes pelo personagem Agostinho, com as suas trapalhadas. É importante também citar a caracterização do figurino e dos objetos de cena, que remetem ao universo kitsch.

Já os Pereira de Pé na cova vão muito além dos Silva, principalmente no quesito bizarrice. Eles não têm dinheiro, não têm instrução, são completamente loucos e têm uma característica fora do comum: constituem um grupo de pessoas excêntricas ao limite, que beiram o absurdo e sobrevivem da morte. 
A referência de Miguel Falabella é direta ao dizer que o Brasil está cheio dessas pessoas e trata os Pereira como a "família Addams do Irajá". Assim como a referência americana, uma família típica por seus hábitos não convencionais, bizarra, excêntrica, que tem prazer na maioria das coisas que pessoas ditas "normais" teriam medo, receio de assumir. Aqueles que os veem e os visitam se assustam ao ver os hábitos "incomuns" do clã.

Sob o ponto de vista estético, as imagens reforçam o gosto duvidoso do suburbano no seu jeito de vestir e de se portar. As profissões também estão ali para confirmar: proprietário de funerária, maquiadora de cadáver, carpideira, motorista, mecânico, garçonete, stripper, funcionário público e vereador. O mau gosto, no sentido literal, está expresso no cardápio das Cachorras Quentes: o x-túmulo, o morte natural (sanduíche natural) e os restos mortais (mexidão).

A falta de instrução é reforçada pelo discurso da inadequação, da não concordância verbal, da simplificação e das equivocadas interpretações dos significados das palavras, como no episódio "Nação laica", exibido em 31 de janeiro de 2013. "Laica" chega a ter o significado de "pessoa afeminada", segundo Alessanderson, e até "derrubada, caída", de acordo com Darlene, personagem de Marília Pêra. Aqui se percebe a utilização do nonsense como estratégia para chocar o telespectador. Os nomes dos personagens também são curiosos por fazer composições bizarras, além de homenagens a atrizes e vilãs de novela (Darlene Glória e Odete Roitman). As opções sexuais também estão lá representadas e quanto a isso não há uma linguagem politicamente incorreta. Não tem essa de lésbica, é sapatão. É travesti mesmo!

O lado chato do politicamente correto está no outro lado da rua, nos confrontos que a família Pereira e amigos têm com o guardião dos bons costumes e da tradição da família, Floriano e a assistente, a Dircéia. Eles condenam o jeito de ser e de viver dos Pereira e amigos e chegam a fazer uma manifestação. Ruço, mesmo não concordando com o estilo de vida adotado de alguns integrantes da família, reage defendendo o direito à liberdade e de viver de um jeito que ele considera apenas diferente. O discurso, apesar de defender a diversidade, não 
alivia e é politicamente incorreto ao atacar Dircéia, chamando-a de baleia e outros bichos gordos, outro reforço da caracterização do machismo suburbano.

\section{Considerações finais}

Levando-se em conta o que foi exposto anteriormente, a conclusão a que poderíamos chegar inicialmente é de que se trata de uma série em forma de pastiche, recheada de clichês, em que se reforçam imagens e preconceitos. Mas não é bem assim.

Pé na cova (2013) pode não ter a morte física como tema central, porém as mortes simbólicas estão ali discutidas, de uma maneira ou de outra: a exclusão social, o degredo, a ignorância, a falta de oportunidades, a fome, o alcoolismo, o preconceito e a miséria do corpo e da alma. Até mesmo o orgasmo, la petit mort. Seria demais fazer drama de tudo isso. Assim, na forma de diálogos nonsense, principalmente nos estabelecidos entre Ruço e Darlene, há espaço para a reflexão. O telespectador é levado a ficar suspenso entre o riso e a perplexidade, entre a estranheza e a identificação. O que se apresenta ao mesmo tempo Ihe diz respeito e não diz respeito a coisa alguma.

\footnotetext{
O povão me entende, eu nunca subestimo o público. O Ruço, que eu acho que é o observador da história, não acha bonito o filho ser um político corrupto, ou a filha tirar a roupa na internet, ou a Darlene ser uma ignorante. Ele é um homem chocado com o mundo que o rodeia, com aquele mundo alucinado a sua volta (FALABELLA, 2013).
}

Neste sentido, há uma provocação a partir da visibilidade de absurdos que provocam o questionamento, a indignação, o inconformismo com certas situações, e o desenvolvimento de um tipo de sabedoria popular a partir da legitimação de uma maneira de existir e viver diferente, mas nem por isso menos digna.

No episódio "Vida de bailarina", exibido em 15 de outubro de 2013, há uma espécie de "acerto de contas" entre as questões da celebridade e do anonimato. A atriz Giovana Antonelli faz pretensamente o papel dela mesma e, quem diria, também vai parar no Irajá. Na história, a celebridade abandona o carro em plena 
avenida Brasil para fugir do bloqueio das pistas feita por traficantes e busca refúgio na casa dos Pereira, no andar de cima da funerária. Logo que ficam sabendo da novidade, os curiosos vão até a casa de Ruço para ver a celebridade. Assim como vários telespectadores, eles reverenciam a atriz, mas trocam nomes, usam o nome do personagem, situação corriqueira e que independe de classe social.

O que se presencia a partir disso é uma transformação em duplo sentido. Os suburbanos aos poucos passam da euforia inicial de idolatria para um tratamento mais próximo e menos verticalizado. A atriz/personagem, por sua vez, em um primeiro momento fica chocada e chega a expressar se aquilo não era uma pegadinha, mas aos poucos se integra à comunidade. Ela chega a participar de uma festa em sua homenagem e dança com Alessanderson, Juscelino, Ruço e até Luz Divina ao som da música "Vida de bailarina", interpretada por Ângela Maria. Ao final ainda é maquiada por Darlene e faz uma sessão de fotos.

Na manhã seguinte, Giovana Antonelli, antes de sair, atende a um pedido de Adenóide. A empregada está com a televisão queimada e precisa saber do último capítulo da novela em que a atriz é protagonista. Giovana Antonelli se aproxima e conta no ouvido dela o final da novela. Ela se despede de todos, mas antes de ir Ruço faz um último comentário: "Eu não sei quem disse, mas disseram que Giovana Antonelli é gente. E hoje eu compro... compro... comprovei isso. Tu é gente". Ao que ela responde: "Dizem que eu sou". Ela pega uma carona com Juscelino no carro funerário e se vai agradecida, dizendo que havia sido muito bom. Todos voltam para os seus mundos iguais e diferentes.

Percebe-se aqui um momento de acerto de contas, em que a figura da atriz percebe a existência, legitima e reconhece naquele lugar a riqueza de práticas culturais, relações sociais e produções de sentido diversas, diferentes e até antagônicas em relação as suas, mas não menos importantes. O subúrbio assim pode ser visto como um espaço ainda pouco explorado, mas rico em termos de questionamento e resistência aos valores hegemônicos, incorporando e produzindo outros sentidos, imagens e sentimentos, remetendo a modos de viver, morar e relacionar-se com a cidade dentro e fora de seus muros concretos e imaginários. 


\section{Referências}

FALABELLA, M. "Miguel Falabella comemora segunda temporada: 'apostei em linguagem nova'". Site TVG. Disponível em: http://gshow.globo.com/programas/ pe-na-cova/Por-Tras-das-Cameras/noticia/2013/09/miguel-falabella-comemorasegunda-temporada-apostei-em-linguagem-nova.html. Acessado em: 12 out. 2013.

GINSBURG, C. O fio e os rastros: verdadeiro, falso, fictício. São Paulo: Companhia das Letras, 2007.

LEVI, G. "Sobre a micro-história". In: A escrita da história: novas perspectivas. BURKE, P. (org.). São Paulo: Editora da Unesp, 1992.

LIMA BARRETO, A. H. Calvário e porres do pingente. Rio de Janeiro: Civilização Brasileira, 1977.

MACIEL, L. A. "Outras memórias nos subúrbios cariocas: o direito ao passado". In: 150 anos de subúrbio carioca. OLIVEIRA, M. P.; FERNANDES, N. N. (orgs.). Rio de Janeiro: Lamparina; Faperj; EdUFF, 2010.

RODRIGUES, N. A vida como ela é. Rio de Janeiro: Nova Fronteira, 2012.

SILVA, M. L. P. "A favela e o subúrbio: associações e dissociações na expansão suburbana da favela". In: 150 anos de subúrbio carioca. OLIVEIRA, M. P.; FERNANDES, N. N. (orgs.). Rio de Janeiro: Lamparina; Faperj; EdUFF, 2010.

SOUZA, R. R. "As representações subalternas dos homens suburbanos". In: 150 anos de subúrbio carioca. OLIVEIRA, M. P.; FERNANDES, N. N. (orgs.). Rio de Janeiro: Lamparina; Faperj; EdUFF, 2010. 


\section{Referências audiovisuais}

ALLEN, W. A rosa púrpura do Cairo. 1985.

FAWCETT, F.; ABREU, F. Kátia Flávia. 1992.

FAWCETT, F.; ABREU, F.; LAUFER. Rio 40 graus. 1992.

HOLANDA, C. B. Subúrbio. Rio de Janeiro: Biscoito Fino, 2006.

I love Lucy. CBS 1951-1957. YouTube. Acessado em: 3 nov. 2013.

Pé na cova. Rede Globo, 2013. YouTube. 